\title{
Heparin-induced thrombocytopenia: An update for the COVID-19 era
}

\author{
J Bailly, ${ }^{1}$ MB ChB Hons, Dip PEC (SA), MMed (Haem), FC Path (SA) Haem; L Haupt, ${ }^{2}$ MB ChB, MMed (Haem), FC Path (SA) Haem; \\ J Joubert, ${ }^{2}$ MB ChB, MMed (Haem), PG Dip (Transfusion Medicine); P Loebenberg, ${ }^{3}$ MB ChB, MMed (Int Med), FCP (SA), \\ Cert Clin Haem (SA); B F Jacobson, ${ }^{4}$ MB ChB, FRCS (Glasg), MMed (Haem), FC Path (SA), PhD (Med); V J Louw, ${ }^{3}$ MB ChB, MMed (Int Med), \\ $\mathrm{PhD}$ (HPE); P F Wessels, ${ }^{5}$ MB ChB, MMed (Haem), Cert Clin Haem (SA); J J Opie, ${ }^{1}$ MB ChB Hons, MRCP (UK), FRCPA (Haem) \\ ${ }^{1}$ Division of Haematology, Department of Pathology, Faculty of Health Sciences, University of Cape Town and National Health Laboratory \\ Service, Groote Schuur Hospital, Cape Town, South Africa \\ ${ }^{2}$ Department of Haematology and Cell Biology, Faculty of Health Sciences, University of the Free State and National Health Laboratory Service, \\ Universitas Academic Laboratories, Bloemfontein, South Africa \\ ${ }^{3}$ Division of Clinical Haematology, Department of Medicine, Faculty of Health Sciences, University of Cape Town, South Africa \\ ${ }^{4}$ Department of Molecular Medicine and Haematology, Faculty of Health Sciences, University of the Witwatersrand and National Health \\ Laboratory Service, Charlotte Maxeke Johannesburg Academic Hospital, Johannesburg, South Africa \\ ${ }^{5}$ Ampath Laboratories, Life Groenkloof Hospital, Tshwane, South Africa
}

Corresponding author: J Bailly (jenique.bailly@uct.ac.za)

The increased use of heparin during the current COVID-19 pandemic has highlighted the risk of a rare but potentially serious complication of heparin therapy, viz. heparin-induced thrombocytopenia (HIT). This is a short review on the pharmacology of heparin and its derivatives, and the pathophysiology of HIT. Guidance on laboratory testing for and clinical management of HIT is presented in accordance with international guidelines. There are important similarities and differences between HIT and the new entity of vaccine-induced immune thrombotic thrombocytopenia, also known as thrombosis with thrombocytopenia syndrome, which clinicians need to be aware of.

S Afr Med J 2021;111(9):841-848. https://doi.org/10.7196/SAMJ.2021.v111i9.15909

Heparin is frequently prescribed for the prevention and treatment of thromboembolic disease. ${ }^{[1]}$ Heparin-induced thrombocytopenia (HIT) is an immune-mediated complication of heparin therapy associated with thrombocytopenia and an increased risk of venous and/or arterial thrombosis, which may be limb- and/or life-threatening. ${ }^{[2]}$ Since heparin is widely used, a high level of awareness of HIT is important. Although rare, HIT is particularly relevant in the current era of COVID-19, when most COVID-19 inpatients receive heparin therapy as thromboprophylaxis. ${ }^{[3]}$ There are important similarities between HIT and vaccine-induced immune thrombotic thrombocytopenia (VITT), including similar pathophysiology involving platelet factor 4 (PF4), increased thrombotic risk and thrombocytopenia. ${ }^{[4]}$

HIT is caused by immunoglobulin G (IgG) autoantibodies that develop in response to heparin exposure. These IgG autoantibodies are directed against PF4/heparin complexes, leading to immune complex formation and subsequent platelet activation. The coagulation cascade is then activated, leading to widespread clot formation. ${ }^{[2,5]}$ Recognition of HIT is critical to prevent and appropriately manage HIT-associated complications. ${ }^{[2]}$

This review includes a short discussion on the pharmacology of heparin and the pathogenesis of HIT, with reference to the recent literature. Guidance on the clinical features, laboratory testing and clinical management of HIT is provided. Key similarities and differences between HIT and VITT are discussed.

\section{Heparin}

\section{Pharmacology}

Heparin is a mixture of negatively charged oligo- and polysaccharides that belong to the glycosaminoglycan (GAG) family of molecules.
The GAG family of molecules includes endogenous heparin-like molecules expressed on endothelial cells. ${ }^{[6]}$ Heparin is isolated from porcine intestinal mucosa and is purified and processed prior to pharmaceutical use. ${ }^{[6,7]}$ Heparin functions primarily by potentiating the anticoagulant action of antithrombin (AT) several thousand-fold, which inhibits activated thrombin (activated factor II). ${ }^{[8]}$ Fig. 1 demonstrates the pharmacological action of heparin and its primary interaction with AT.

\section{Heparin formulations}

The two major heparins in clinical practice are unfractionated heparin (UFH) and low-molecular-weight heparin (LMWH). Table 1 summarises the key differences between UFH and LMWH.

$\mathrm{UFH}$ is comprised of a heterogeneous mixture of oligo- and polysaccharide chains. This structural heterogeneity results in unpredictable bioactivity and physiological effects, which mandates regular laboratory monitoring. UFH also interacts with numerous proteins and cells in vivo, resulting in certain off-target effects (Table 1). ${ }^{[1,12]} \mathrm{LMWH}$ is a derivative of UFH resulting from the controlled depolymerisation of UFH polysaccharide chains. Depolymerisation of UFH results in heparin fragments of shorter length and therefore lower molecular weight. ${ }^{[7,12,13]}$ The various manufacturing techniques employed by pharmaceutical manufacturers result in LMWH of different molecular weights and pharmacological properties. The ratio of anti-factor Xa to anti-factor IIa therefore differs slightly between different LMWH products. ${ }^{[1,13]}$ The pentasaccharide unit of heparin is the shortest portion of the heparin molecule able to bind and activate AT. This pentasaccharide unit facilitates the inhibition of activated factor X only. A longer 


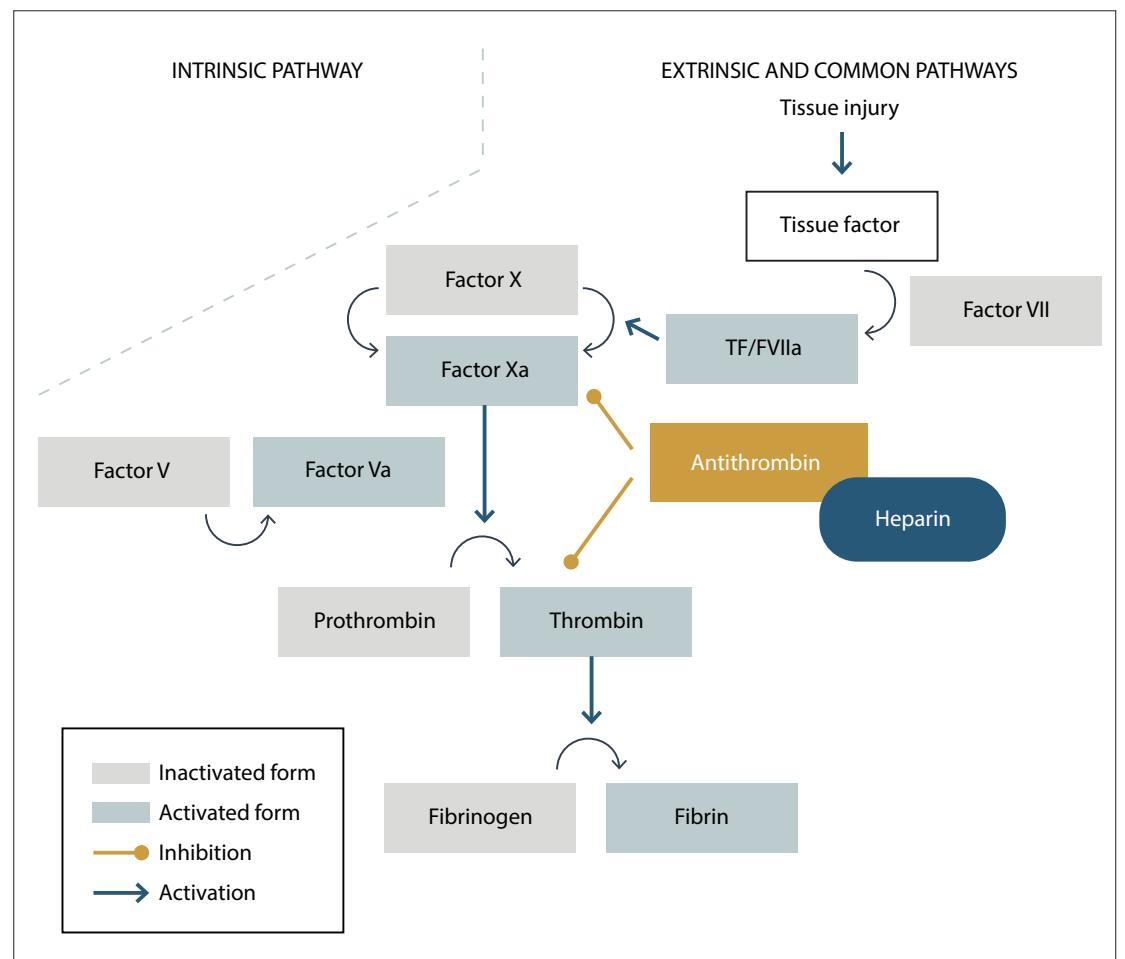

Fig. 1. The interaction between heparin and AT within the coagulation cascade. AT is a serine protease inhibitor and major natural anticoagulant. Heparin binding to AT activates it into a potent inhibitor of thrombin (activated factor II) and activated factor $X{ }^{[8]}(A T=$ antithrombin; TF $=$ tissue factor; FVIIa $=$ activated factor VII; Factor Xa = activated factor X; Factor Va = activated factor V.)

heparin chain ( 18 saccharide sequences) is required for AT to exert its inhibitory effect on thrombin (activated factor II). ${ }^{[7]}$

LMWH is now more widely used than UFH owing to its ease of administration, more predictable pharmacological effects, improved side-effect profile and equivalence in efficacy and safety. ${ }^{[1,13]}$ However, owing to its rapid onset of action and reversibility, UFH remains the anticoagulant of choice in certain clinical scenarios. ${ }^{[2]}$

\section{Heparin-induced thrombocy topenia}

Two types of HIT have been described, which differ in their underlying pathogenesis and clinical significance (Table 2).

\section{Pathophysiology of HIT}

Platelets have a lifespan of $7-10$ days and play an essential role in primary haemostasis. ${ }^{[14]}$ Platelets store haemostatic mediators within their granules, including PF4, which is a positively charged protein released upon platelet activation. Thereafter PF4 readily binds negatively charged endogenous heparin-like molecules present on endothelial cells and high-molecular-weight fragments of heparin. Because PF4 has a high affinity for heparin, circulating PF4/heparin complexes readily form in the circulation. ${ }^{[2]}$
These PF4/heparin complexes can be immunogenic and result in IgG antibody formation, which occurs more commonly with UFH than LMWH use. The anti-PF4/ heparin IgG antibodies bind to PF4/heparin complexes within the circulation, leading to platelet, monocyte, endothelial cell and neutrophil activation. These interactions lead to subsequent profound activation of coagulation and thrombus formation. ${ }^{[2,5,15]}$ Fig. 2 demonstrates the pathogenesis of clinically significant HIT.

Not all circulating PF4/heparin antibodies can activate platelets. The iceberg model of HIT (Fig. 3) explains the relationship between the higher frequency of PF4/heparin antibody detection in immunoassays (see the section on laboratory diagnosis of HIT) and the much lower prevalence of clinically significant HIT. ${ }^{[16]}$

\section{Prevalence and clinical manifestations of HIT \\ Prevalence}

The prevalence of HIT is reported as up to $2.7 \%,{ }^{[17]}$ depending on the type and dose of heparin used (UFH v. LMWH), previous heparin exposure, the clinical circumstances and duration of therapy. ${ }^{[2,17]}$ Rarely, HIT may also occur without previous heparin exposure, so-called spontaneous HIT. ${ }^{[2]}$
Clinical conditions associated with the release of PF4 such as post-surgery, trauma or sepsis are associated with an increased risk of HIT. ${ }^{[2,18]}$ Table 3 summarises the prevalence of HIT reported in the literature for different clinical scenarios.

\section{Clinical manifestations}

Thrombocytopenia in temporal association with heparin is noted in up to $95 \%$ of patients diagnosed with HIT. Classically the platelet count decreases by $30-50 \%$ from baseline, which results in moderate thrombocytopenia (nadir platelet count $50-70 \times 10^{9} / \mathrm{L}$ ). ${ }^{[2]}$ However, if the baseline platelet count is high, the platelet count may drop by $50 \%$ but still be within the normal range. The nadir in platelet count typically occurs within 5 10 days after commencing heparin therapy. Thrombocytopenia can occur within 24 hours if heparin exposure occurred within the preceding 100 days, and where the patient still has circulating anti-PF4/heparin antibodies. ${ }^{[2,18]}$ Post cardiopulmonary bypass surgery, a drop in platelet count is common within the first 72 hours after surgery, which is multifactorial; however, platelet count recovery postoperatively followed by a subsequent drop in platelet count 5 - 10 days after heparin exposure is highly suspicious of HIT ${ }^{[18]}$ In view of the difficulty of evaluation for HIT post cardiac surgery, a scoring system specifically for this situation has been proposed. ${ }^{[21]}$

Approximately $50 \%$ of patients who develop clinically significant HIT also develop thrombosis. ${ }^{[13]}$ HIT-associated thrombosis can affect any vascular bed including venous and arterial. The venous system, particularly at vascular catheter sites, is most commonly affected. Venous limb gangrene, skin necrosis and bilateral adrenal haemorrhage may occur as a result of widespread thrombosis. The severity of thrombocytopenia inversely correlates with thrombotic risk. ${ }^{[2]}$ Bleeding resulting from HIT is extremely rare. ${ }^{[18]}$

Upon diagnosis of HIT, immediate cessation of heparin and prompt anticoagulation with an alternative agent should ensue, since patients are profoundly prothrombotic. After cessation of heparin, up to $65 \%$ of patients will recover their platelet counts to baseline levels within 7 days. ${ }^{[2]}$ The prothrombotic phase of HIT continues until the platelet count has returned to baseline. ${ }^{[21]}$

\section{Ts clinical probability scoring system}

If a patient is receiving heparin therapy and HIT is suspected, the probability of HIT should be determined using the 4Ts 
Table 1. Comparison between UFH and LMWH ${ }^{[9,10]}$

\begin{tabular}{|c|c|c|}
\hline Features & UFH & LMWH \\
\hline Source & Porcine intestinal mucosa & Fractionated from UFH \\
\hline Molecular weight & $3000-15000$ daltons & $3000-5000$ daltons \\
\hline Half-life & $45-60$ minutes & 240 minutes \\
\hline Administration & Continuous intravenous infusion & Subcutaneous administration \\
\hline \multirow[t]{4}{*}{ Pharmacokinetics } & $\begin{array}{l}\text { The heterogeneity of polysaccharide chains } \\
\text { affects drug potency and clearance between } \\
\text { individuals }\end{array}$ & More homogeneous polysaccharide chains than UFH \\
\hline & - $<50 \%$ bioavailability & - $90 \%$ bioavailability \\
\hline & $\begin{array}{l}\text { Complex mixed-order kinetics due to } \\
\text { variable interaction with endogenous } \\
\text { proteins and endothelial cells }\end{array}$ & $\begin{array}{l}\text { - Shows first-order kinetics with a clear dose-response } \\
\text { relationship }\end{array}$ \\
\hline & $\begin{array}{l}\text { - Clearance via the RES (renal clearance is } \\
\text { dose dependent and saturable) }\end{array}$ & $\begin{array}{l}\text { - Renal clearance (not dose dependent, non-saturable } \\
\text { and linear) }\end{array}$ \\
\hline Monitoring & $\begin{array}{l}\text { Routine monitoring with aPTT; ACT in high- } \\
\text { dose UFH }\end{array}$ & Generally not required (with exceptions ${ }^{\star}$ ) \\
\hline Molecular targets & $\begin{array}{l}\text { Anti-factor } \mathrm{Xa} \text { and anti-factor IIa activity in a } \\
1: 1 \text { ratio }\end{array}$ & $\begin{array}{l}\text { Preferentially binds and inactivates factor Xa with } \\
\text { a } 2 \text { - 5:1 anti-factor Xa to anti-factor IIa ratio }\end{array}$ \\
\hline Reversal & Protamine sulphate ${ }^{\dagger}$ & Partial reversal with protamine sulphate ${ }^{\dagger}$ \\
\hline Major side-effects & $\begin{array}{l}\text { - Bleeding } \\
\text { - } \text { HIT in } \sim 2.7 \%^{\ddagger} \\
\text { - Cutaneous hypersensitivity reaction if given } \\
\text { s.c. in } \sim 7.5 \% \\
\text { - Osteoporosis in } \sim 2 \%^{\S}\end{array}$ & $\begin{array}{l}\text { - Bleeding } \\
\text { - HIT and osteoporosis (<1\% of cases) } \\
\text { - Cutaneous hypersensitivity reaction in } ~ 7.5 \%\end{array}$ \\
\hline \multicolumn{3}{|c|}{ 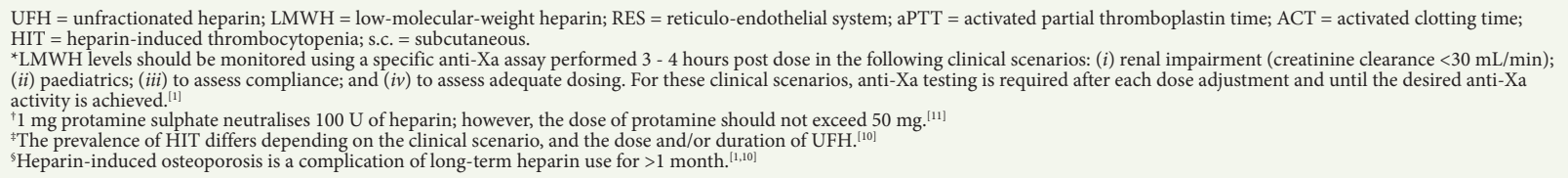 } \\
\hline
\end{tabular}

clinical probability scoring system. ${ }^{[18,21]}$ The 4 Ts score provides information on the likelihood of HIT and guides acute management and laboratory testing. Lo et al. ${ }^{[19]}$ first introduced and validated the 4Ts scoring system for HIT in 2003. Four typical features (the ' $4 \mathrm{Ts}$ ') are incorporated and the likelihood of HIT is estimated based on the cumulative score (Table 4). ${ }^{[19]}$ The scoring system has an excellent negative predictive value if a low probability score of $0-3$ is calculated $(>0.98))^{[22]}$ This means that a negative screening result is very helpful to exclude HIT.

\section{Monitoring of platelet counts to screen for HI'T}

The British Committee for Standards in Haematology (BCSH) recommends monitoring platelet counts in select patients receiving heparin therapy. These recommendations have been adapted and are presented in Table 5. In addition, recommendations from local experts on platelet count monitoring in patients receiving LMWH, or hospitalised with COVID-19 and receiving heparin therapy, are presented.

\section{Laboratory diagnosis of HIT}

The laboratory tests used for the screening and/or diagnosis of HIT can be divided into two main groups. The first group are immunoassays used to screen for anti-PF4/heparin antibodies. These immunoassays are used as an initial screening step in patients with an intermediate to high 4 Ts score ${ }^{[2]}$ For most patients with a high 4 Ts score (score of $6-8$ ), the presence of a positive HIT immunoassay confirms the diagnosis of HIT without the need for confirmatory testing with a functional HIT assay. ${ }^{[2,21]}$ Screening for anti-PF4/ heparin antibodies is offered by two public sector laboratories in South Africa (SA), namely the National Health Laboratory Service (NHLS) at Groote Schuur Hospital in Cape Town and the Special Haemostasis Laboratory at Universitas Hospital in Bloemfontein. Ampath Laboratories offers an enzyme-linked immunosorbent assay (ELISA) screening test. For patients with an intermediate 4Ts score (score of 4 - 5), further functional testing is required to confirm the functional activity of the anti-PF4/heparin antibodies detected. ${ }^{[1,18]}$ This is due to the high rate of asymptomatic seroconversion seen in patients exposed to heparin. Up to $50 \%$ of patients develop anti-PF4/ heparin antibodies (particularly in cardiac bypass surgery), whereas only 0.2 - $5 \%$ will develop clinically significant complications. ${ }^{[2,16]}$

The functional assays for HIT are platelet activation assays that assess platelet activation in the presence of anti-PF4/heparin antibodies and heparin. These are technically difficult tests and not routinely performed. ${ }^{[2,23]}$ Currently, the Special Haemostasis Laboratory at Universitas Hospital is the only laboratory offering functional HIT testing nationally. The heparin-induced platelet aggregation assay (HIPA) offers high specificity $(>95 \%)$ and a high positive predictive value $(89-100 \%)$ for HIT. ${ }^{[2,23]}$ The HIPA assay indirectly assesses the ability of the anti-PF4/heparin antibodies to 
Table 2. Classification of heparin-induced thrombocytopenia ${ }^{[2]}$

\begin{tabular}{|c|c|c|}
\hline Features & Cause of thrombocytopenia & Clinical effect \\
\hline Type I & Heparin-induced platelet agglutination & $\begin{array}{l}\text { Clinically insignificant transient, mild thrombocytopenia } \\
\leq 3 \text { days of heparin therapy } \\
\text { Platelet count } \geq 100 \times 10^{9} / \mathrm{L}\end{array}$ \\
\hline Type II $^{*}$ & Immune-mediated $^{\dagger}$ & $\begin{array}{l}\text { Serious with potential limb- or life-threatening } \\
\text { complications }^{\ddagger} \\
\text { Platelet count nadir typically } 50-70 \times 10^{9} / \mathrm{L}\end{array}$ \\
\hline
\end{tabular}

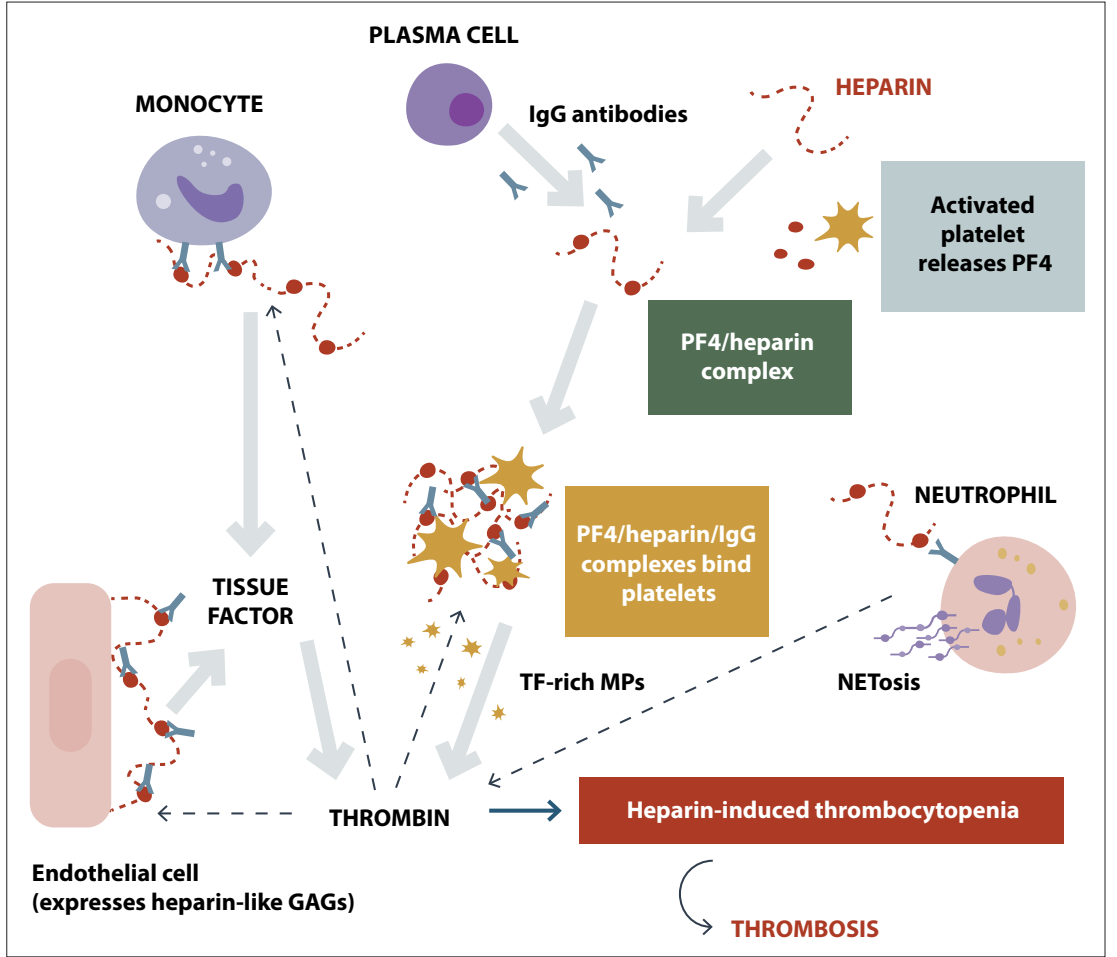

Fig. 2. Pathogenesis of clinically significant heparin-induced thrombocytopenia. ${ }^{[2,5]}$ Plasma cells produce and secrete specific IgG antibodies in response to circulating PF4/heparin complexes. The antibody/PF4/heparin immune complexes then bind platelets, monocytes and neutrophils via their $F c y$ receptors, resulting in platelet and immune system activation. Procoagulant mediators such as TF-rich microparticles are released, and NETosis occurs. NETosis due to neutrophil extracellular trap formation, and the release of TF-rich microparticles result in activation of the coagulation cascade and thrombin formation. Thrombin, a potent activator of platelets, monocytes and endothelial cells, further potentiates their activation and TF production. Widespread activation of the coagulation cascade results in thrombus formation in numerous organ systems and tissues, resulting in ischaemia and localised necrosis. The activation and incorporation of platelets within the thrombi, as well as increased peripheral sequestration by the spleen, result in thrombocytopenia. (IgG = immunoglobulin G; PF4 = platelet factor 4; TF = tissue factor; $M P s=$ microparticles; GAGs = glycosaminoglycans.)

cause platelet activation and aggregation in the presence of heparin. ${ }^{[23]}$ All public sector HIT tests should be discussed with either the NHLS Universitas Special Haemostasis Laboratory at +27514053040 or the NHLS Groote Schuur Haematology Laboratory at +2721 4043191 for testing recommendations and sample requirements.

Owing to the high prevalence of asymptomatic seroconversion with heparin
Laboratory error or differences in antibody specificity can rarely result in a false-negative immunoassay. Clinical re-evaluation and repeat HIT testing, including a functional assay, is therefore indicated in cases where the clinical suspicion for HIT remains high. ${ }^{[21]}$

\section{HIT and COVID-19}

The World Health Organization declared SARS-CoV-2 a pandemic in March 2020. By the end of June 2021, the number of SARSCoV-2 infections exceeded 178118597 confirmed cases worldwide, with >3 864180 deaths reported. ${ }^{[25]}$ SARS-CoV-2 causes COVID-19, which in severe cases results in immune dysregulation with acute respiratory distress syndrome, multiorgan dysfunction, and thromboembolism due to the activation of the coagulation system and endothelium. ${ }^{[26,27]}$ Haemostatic abnormalities may occur, resulting in a hypercoagulable state often complicated by venous thrombosis, pulmonary embolism or stroke. ${ }^{[3,27]}$ Guidelines support heparin therapy, typically LMWH, for the prevention and treatment of thromboembolic disease in COVID-19 ${ }^{[28,29]}$ because of its antiinflammatory properties, ${ }^{[9]}$ efficacy, large body of clinical experience, availability of laboratory monitoring, and predictable pharmacokinetics.

Although both COVID-19 and HIT are hypercoagulable disorders with a significant risk of thrombotic complications, management differs markedly. In COVID-19, heparin is the mainstay of thromboprophylaxis and therapy, whereas immediate discontinuation of heparin is absolutely essential in the management of HIT. ${ }^{[2,3]}$ Patients with severe COVID-19 may receive heparin for prolonged periods of time (commonly $>5$ days), which increases their risk of developing HIT. An increased frequency of anti-PF4/heparin antibodies has been reported in severe COVID-19. ${ }^{[3,24]}$ However, the true prevalence of HIT in COVID-19 remains uncertain..$^{[3]}$ 
Table 3. The prevalence of clinically significant HIT for different patient groups ${ }^{[2,17,19,20]}$

\begin{tabular}{ll}
\hline Variable & Prevalence of clinically significant HIT \\
\hline LMWH v. UFH, prophylactic doses & $0 \% \mathrm{v} .2 .7 \%(p=0.0018)^{[17]}$ \\
Clinical groups & $1.2 \% \mathrm{v} .1 .5 \%(p=0.246)^{[20]}$ \\
& Higher prevalence in surgical v. non-surgical patients; females v. males; \\
Date of last heparin exposure & adult vaediatric patients \\
Duration of heparin exposure & Higher prevalence if heparin was used within the previous 100 days \\
HIT = heparin-induced thrombocytopenia; LMWH $=$ low-molecular-weight heparin; UFH = unfractionated heparin.
\end{tabular}

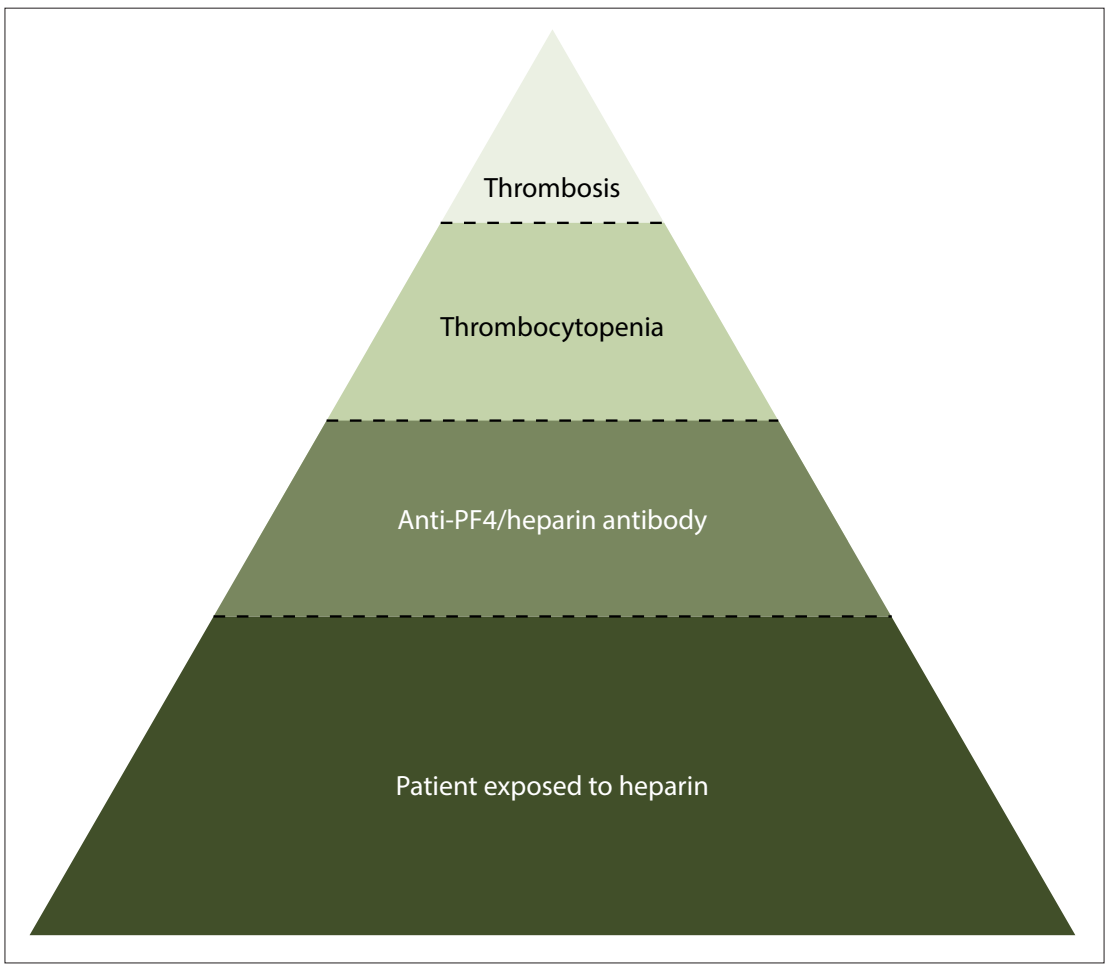

Fig. 3. Iceberg model for heparin-induced thrombocytopenia. ${ }^{[16]}$ (PF4= platelet factor 4.$)$

Clinical distinction between severe COVID-19 and HIT is often challenging. Thrombotic complications (thrombosis at venous, arterial and unusual sites) occur in $\sim 50 \%$ of severe COVID-19 and 50\% of clinically significant HIT. Venous thromboses are more frequent than arterial thromboses in both COVID-19 and HIT. Thrombocytopenia and disseminated intravascular coagulation (DIC) may occur in severe fatal COVID-19, and moderate thrombocytopenia is found in HIT. ${ }^{[3]}$

Until further information is available regarding the true prevalence of HIT in COVID-19, we recommend baseline platelet counts and alternate-day platelet count monitoring for hospitalised COVID-19 patients receiving any form of heparin therapy (UFH or LMWH; prophylactic, intermediate or therapeutic dosing; dialysis catheter flushing). Additionally, HIT testing should be no cases of VITT. ${ }^{[34]}$ The underlying pathophysiological mechanisms that lead to VITT remain to be clarified.

The pathological findings in VITT and HIT are similar. In both conditions, patients develop high levels of antibodies to PF4 as identified by the PF4 antibody ELISA test. In contrast to HIT, in VITT the binding of antibodies to PF4 and activation of platelets occur in the absence of heparin. ${ }^{[35]}$ Another difference between HIT and VITT is that the platelet nadir tends to be much lower in VITT compared with HIT. A high frequency of decompensated DIC has also been reported in patients with VITT. ${ }^{[4]}$

An adapted 4Ts scoring system has been proposed to predict the pretest probability of VITT. Laboratory testing is recommended in individuals with an intermediate or high score. ${ }^{[4]}$ Current national and international guidelines recommend that the diagnosis of VITT is confirmed with an approved PF4 antibody ELISA test and that the rapid immunoassays used to detect HIT should not be used unless they have been specifically validated for the diagnosis/ exclusion of VITT. ${ }^{[35,36]}$

The management of VITT is similar to that of HIT (see below) with the addition of high-dose intravenous immunoglobulin. A second dose of the culprit vaccine, if required, should be avoided. ${ }^{[36]}$

\section{Vaccine-induced immune thrombotic thrombocytopenia}

In the wake of large-scale SARS-CoV-2 vaccine roll-outs, a novel syndrome characterised by thrombosis (often at unusual sites) and thrombocytopenia has been described. This syndrome, named VITT, typically develops 5 - 24 days after vaccination with an adenoviral vector vaccine. The two currently available adenoviral vector vaccines are ChAdOx1 nCoV19 vaccine (AstraZeneca) ${ }^{[30-32]}$ and Ad26. COV2.S vaccine (Johnson \& Johnson/ Janssen). ${ }^{[33]}$ At the time of writing (June 2021), the Ad26.COV2.S had been administered to 490000 South Africans as part of the Sisonke Trial. Data published on the first 288000 participants revealed

\section{Management of HITT}

The BCSH and the American Society of Hematology (ASH) have provided guidelines for the management of HIT. ${ }^{[18,21]}$ The diagnosis and management of HIT should occur in consultation with a clinical haematologist experienced in managing HIT.

In patients with suspected HIT (intermediate or high 4Ts score), while awaiting HIT laboratory test results (Fig. 4), heparin therapy should immediately cease and an alternative anticoagulant should be started. Data on the comparative safety and efficacy of the various nonheparin anticoagulants is unclear owing to 
Table 4. The 4Ts clinical probability scoring system for heparin-induced thrombocytopenia ${ }^{[19] *}$

\begin{tabular}{|c|c|c|c|}
\hline $4 \mathrm{Ts}$ & 2 points & 1 point & 0 points \\
\hline Thrombocytopenia & $\begin{array}{l}>50 \% \text { drop and platelet nadir } \\
\geq 20 \times 10^{9} / \mathrm{L}\end{array}$ & $\begin{array}{l}30-50 \% \text { drop or platelet } \\
\text { nadir } 10-19 \times 10^{9} / \mathrm{L}\end{array}$ & $\begin{array}{l}<30 \% \text { drop or platelet } \\
\text { nadir }<10 \times 10^{9} / \mathrm{L}\end{array}$ \\
\hline Timing of platelet count fall & $\begin{array}{l}\text { Clear onset } 5 \text { - } 10 \text { days after heparin } \\
\text { exposure or platelet fall } \leq 1 \text { day (prior } \\
\text { heparin exposure within } 30 \text { days) }\end{array}$ & $\begin{array}{l}\text { Onset after day } 10 \text { or platelet fall } \\
\leq 1 \text { day (prior heparin exposure in } \\
\text { preceding } 30-100 \text { days) }\end{array}$ & $\begin{array}{l}<4 \text { days with no prior } \\
\text { heparin exposure }\end{array}$ \\
\hline Thrombosis $^{\dagger}$ & Confirmed new thrombosis ${ }^{\ddagger}$ & $\begin{array}{l}\text { Progressive or recurrent } \\
\text { thrombosis or possible new } \\
\text { (unconfirmed) thrombosis }\end{array}$ & None \\
\hline $\begin{array}{l}\text { Other cause for } \\
\text { thrombocytopenia favoured }\end{array}$ & No & Possible & Likely \\
\hline \multicolumn{4}{|c|}{$\begin{array}{l}\text { thrombocytopenia favoured } \\
\text { High probability: } 6-8 \text {; Intermediate probability: } 4-5 \text {; Low probability: } 0-3\end{array}$} \\
\hline
\end{tabular}

${ }^{\ddagger}$ Patients with skin necrosis at the heparin injection site or acute systemic reaction after UFH bolus score 2 points even in the absence of confirmed thrombosis. ${ }^{[17]}$

Table 5. Recommendations for the diagnosis and management of HIT

\section{Platelet monitoring}

- A baseline platelet count should be performed prior to starting heparin therapy.*

- If heparin exposure occurred during the preceding 100 days, monitoring of the platelet count should commence on day 0 of heparin exposure and repeated at 24 hours. Monitoring is recommended until heparin is stopped.*

- For patients receiving UFH, alternate-day platelet counts should be performed from days 4 to 14 or until heparin is stopped.*

- For patients receiving therapeutic-dose LMWH, platelet counts should ideally be performed every 5 days from days 4 to 14 or until heparin is stopped. ${ }^{+}$

- For medical patients receiving prophylactic-dose LMWH, platelet counts should ideally be performed once a month until heparin is stopped. ${ }^{\dagger}$

- For obstetric patients receiving prophylactic-dose LMWH, platelet counts should ideally be performed once a month, or at least once a trimester. ${ }^{\dagger}$

- For hospitalised COVID-19 patients receiving any form of heparin, alternate-day platelet counts should be performed from days 4 to 14 or until heparin is stopped. ${ }^{*}$

Clinical diagnosis of HIT

- The 4Ts score should be used to determine the pretest probability of HIT (Table 4).

Laboratory diagnosis of HIT $^{\S}$

- HIT testing should be performed in all patients with an intermediate/high pretest probability 4 Ts score.

- HIT testing is not recommended for patients with a low 4Ts score.

- The diagnosis of HIT can be made with a high 4Ts score and positive HIT immunoassay antibody testing.

- The diagnosis of HIT can be made with an intermediate 4Ts score, positive HIT antibody and functional assay.

Management of HIT

- In patients with an intermediate or high $4 \mathrm{~T}$ score (while awaiting the HIT test results), heparin should be stopped, and an alternative anticoagulant started at therapeutic doses.

- Warfarin therapy should be avoided in the acute phase of HIT and until the platelet count has recovered.

- Contraindications to and dose adjustments of alternative anticoagulants should be followed as for non-HIT VTE.

- Alternative anticoagulants include fondaparinux (subcutaneous), rivaroxaban (oral) or argatroban (intravenous).

- Platelet transfusions should be avoided.

HIT = heparin-induced thrombocytopenia; $\mathrm{UFH}=$ unfractionated heparin; $\mathrm{LMWH}=$ low-molecular-weight heparin; $\mathrm{VTE}=$ venous thromboembolism. ${ }^{*}$ Based on British Committee for Standards in Haematology recommendations (all graded 2C). ${ }^{118}$

'Recommendations based on local expert opinion and consensus agreement.
₹Recommendation based on the higher frequency of anti-PF4/heparin antibodies detected in severe COVID-19; however, the true prevalence of HIT in this patient group is currently uncertain. ${ }^{[3,24]}$ ${ }^{5} \mathrm{HIT}$ testing is indicated if uncertainty about the correct 4 Ts score exists.

a lack of adequate randomised controlled trials. ${ }^{[37]}$ The choice of alternative anticoagulant will depend on clinician experience, drug availability, cost, expected drug-drug interactions, availability of laboratory testing for drug monitoring, patient age, organ function, weight, comorbidities and bleeding risk, as well as other established factors. ${ }^{[21]}$ For most clinically stable patients without an excessive bleeding risk, fondaparinux or direct oral anticoagulants (DOACs) such as rivaroxaban are reasonable choices for the initial treatment of acute HIT. ${ }^{[21]}$
Currently, the BCSH and ASH guidelines recommend that the alternative anticoagulant be started at therapeutic dose (or doseadjusted according to weight, creatinine clearance and/or liver function as per pharmaceutical guidelines). ${ }^{[18,21]}$

The duration of anticoagulant therapy for patients with confirmed HIT depends on the initial indication for heparin therapy (prophylaxis v. treatment of thromboembolic disease), and whether there is HIT without thrombosis (so-called 'isolated HIT') or HIT with thrombosis. In patients with confirmed HIT without thrombosis, 
anticoagulation should continue for at least 4 weeks and until the platelet count has recovered (platelet count $\geq 150 \times 10^{9} / \mathrm{L}$ ). In patients with HIT-associated thrombosis (including those with asymptomatic thrombosis), the patient should be treated as per thrombosis therapeutic guidelines for a minimum of 3 - 6 months. ${ }^{[21]}$

Fig. 4. Algorithm for the diagnosis and early management of heparin-induced thrombocytopenia. ${ }^{[2,18,21]}$ $\left(H I T=\right.$ heparin-induced thrombocytopenia; PF4 = platelet factor $4 ;{ }^{\star}$ For anti-PF4/heparin complex antibodies detected via immunoassay.)

Fondaparinux, a synthetic pentasaccharide heparin, exerts its anticoagulant effect via the selective binding of AT. It is structurally similar to LMWH and could trigger antiPF4/heparin antibody formation and release.

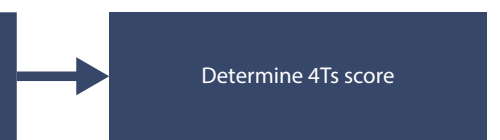

\section{Alternative anticoagulation \\ Fondaparinux} alternatives to fondaparinux and can be considered if an intravenous anticoagulant with a shorter half-life is desired. ${ }^{[18,21]}$ These intravenous agents are not widely available in SA, but may be accessed under the South African Health Products Regulatory Authority (SAHPRA) section 21 programme.

The American College of Chest Physicians Evidence-Based Clinical Practice Guidelines for antithrombotic therapy and prevention of thrombosis ${ }^{[38]}$ recommend fondaparinux (grade $2 \mathrm{C}$ recommendation) in pregnant patients with HIT, if danaparoid is not available. ${ }^{[38]}$

\section{Direct oral anticoagulants}

DOACs do not cross-react with anti-PF4/ heparin antibodies. Unlike warfarin, the DOACs have a fast onset of action, do not require routine monitoring and do not cause a decrease in protein $\mathrm{C}$ activity ${ }^{[39]} \mathrm{A}$ recent systematic review and meta-analysis found that DOACs appear as safe and effective in the treatment of HIT as fondaparinux and other intravenous anticoagulants. ${ }^{[35]}$

The ASH 2018 guidelines $^{[21]}$ state that the DOACs (rivaroxaban, apixaban or dabigatran) are reasonable choices for the treatment of most patients with acute HIT and are suitable alternatives to warfarin following platelet count recovery (so-called subacute HIT). The majority of published clinical experience is with rivaroxaban, an anti-factor Xa inhibitor, which is currently the preferred DOAC in the setting of HIT. The DOACs are, however, not recommended

Table 6. Intravenous anticoagulants recommended by the British Committee for Standards in Haematology and the American Society of Hematology for the treatment of acute heparin-induced thrombocytopenia ${ }^{[18,21]}$

\begin{tabular}{|c|c|c|c|}
\hline Drug & Drug class and administration & Laboratory monitoring & Cost per day ${ }^{\star}$ \\
\hline Argatroban & $\begin{array}{l}\text { Direct thrombin inhibitor } \\
\text { Continuous IV infusion }\end{array}$ & $\begin{array}{l}\text { Dose-adjusted according to aPTT } \\
\text { (1.5 - } 3 \text { times patient baseline) }\end{array}$ & ZAR6 730.73 \\
\hline Bivalirudin $^{\dagger}$ & $\begin{array}{l}\text { Direct thrombin inhibitor } \\
\text { Continuous IV infusion }\end{array}$ & $\begin{array}{l}\text { Dose-adjusted according to aPTT } \\
(1.5-2.5 \text { times patient baseline) }\end{array}$ & ZAR37 031.00 \\
\hline Danaparoid & $\begin{array}{l}\text { Heparinoid and indirect factor Xa inhibitor } \\
\text { Bolus followed by IV infusion }\end{array}$ & $\begin{array}{l}\text { Anti-factor Xa with drug-specific } \\
\text { calibrant (monitoring generally not } \\
\text { required) }\end{array}$ & $\begin{array}{l}\text { First day: ZAR23 } 116.60 \\
\text { Subsequent days: ZAR3 } 054.08\end{array}$ \\
\hline
\end{tabular}


in patients with HIT complicated by limb- or life-threatening thrombosis, when a parenteral anticoagulant is preferred. The contraindications to and indications for laboratory monitoring are the same as for non-HIT venous thromboembolism. ${ }^{[21]}$

\section{Vitamin $\mathrm{K}$ antagonists}

The use of a vitamin $\mathrm{K}$ antagonist (VKA) such as warfarin is not recommended in the acute phase of HIT, and should be withheld until the platelet count is $\geq 150 \times 10^{9} / \mathbf{L}^{[18]}$ Protein $C$, a vitamin $\mathrm{K}$-dependent natural anticoagulant, has a short half-life and is rapidly depleted upon commencing VKA therapy. A decrease in protein $\mathrm{C}$ activity during the acute phase of HIT increases the risk of thrombosis, venous limb gangrene and skin necrosis. ${ }^{[2]}$

Warfarin is recommended as long-term anticoagulation therapy of HIT-associated thrombosis, but only after the platelet count has recovered to $\geq 150 \times 10^{9} / \mathrm{L}$. Overlap with a non-heparin anticoagulant is recommended for at least 5 days and until the INR is within the therapeutic range. If the patient is on VKA therapy when HIT develops, VKA therapy should be stopped and the patient should receive parenteral vitamin $\mathrm{K}$ reversal after an alternative nonheparin anticoagulant at an appropriate dose has been started. ${ }^{[18,39]}$

\section{Platelet transfusion}

Platelet transfusions in HIT may precipitate or worsen thrombosis. Platelet transfusions should be avoided unless the patient is actively bleeding. ${ }^{[18]}$

\section{Surgery}

The BCSH guidelines recommend postponing elective surgical procedures requiring anticoagulant therapy until the patient tests negative for anti-PF4/heparin antibodies. For patients with antiPF4/heparin antibodies in whom urgent surgery is required, nonheparin anticoagulant therapy, if indicated, is recommended. ${ }^{[18]}$

\section{Conclusions}

HIT is an immune-mediated and potentially limb- and lifethreatening complication of heparin therapy. Early diagnosis of HIT is essential to prevent complications and preserve life. The monitoring of platelet counts in certain at-risk groups on heparin therapy is important and ensures the early identification of possible HIT. The 4Ts score is used to estimate the pretest probability of HIT, and guides laboratory testing and acute management. With the increased use of heparin during the COVID-19 pandemic and the associated risk of HIT, a high level of awareness is of paramount importance.

\section{Declaration. None.}

Acknowledgements. The authors thank Lezanne Cloquet for the construction of the tables and editing of the figures.

Author contributions. All authors were involved in the review of the literature, writing and revision of the article, and approval of the final version. Funding. None.

Conflicts of interest. None.

1. Baglin T, Barrowcliffe TW, Cohen A, Greaves M; British Committee for Standards in Haematology Guidelines on the use and monitoring of heparin. Br J Haematol 2006;133(1):19-34. https://doi. org/10.1111/j.1365-2141.2005.05953.x

2. Arepally GM. Heparin-induced thrombocytopenia. Blood 2017;129(21):2864-2872. https://doi. Arepally GM. Heparin-induced
org/10.1182/blood-2016-11-709873

3. Warkentin TE, Kaatz S. COVID-19 versus HIT hypercoagulability. Thromb Res 2020;196:38-51. https:// Warkentin TE, Kaatz S. COVID-19 vers
doi.org/10.1016/j.thromres.2020.08.017

4. Warkentin TE, Cuker A. COVID-19: Vaccine-induced immune thrombotic thrombocytopenia (VITT).

4. Warkentin TE, Cuker A. COVID-19: Vaccine-induced immune thrombotic thrombocytopenia (VITT).
UpToDate, last updated 1 July 2021. https://www.uptodate.com/contents/covid-19-vaccine-inducedimmune-thrombotic-thrombocytopenia-vitt (accessed 6 July 2021).
5. Chong BH. Evolving concepts of pathogenesis of heparin-induced thrombocytopenia: Diagnostic and therapeutic implications. Int J Lab Hematol 2020;42(Suppl 1):25-32. https://doi.org/10.1111/ijlh.13223 Shriver Z, Capila I, Venkataraman G, Sasisekharan R. Heparin and heparan sulfate: Analyzing structure 6. Shriver Z, Capila I, Venkataraman G, Sasisekharan R. Heparin and heparan sulfate: Analyzing structure
and microheterogeneity. Handb Exp Pharmacol 2012;207:159-176. https://doi.org/10.1007/978-3-64223056-1_8

7. Oduah EI, Linhardt RJ, Sharfstein ST. Heparin: Past, present, and future. Pharmaceuticals 2016;9(3):38. https://doi.org/10.3390/ph9030038

8. Gray E, Hogwood J, Mulloy B. The anticoagulant and antithrombotic mechanisms of heparin. Handb Exp Pharmacol 2012;207:43-61. https://doi.org/10.1007/978-3-642-23056-1_3

9. Buijsers B, Yanginlar C, Maciej-Hulme ML, de Mast Q, van der Vlag J. Beneficial non-anticoagulant mechanisms underlying heparin treatment of COVID-19 patients. EBioMedicine 2020;59:102969. https://doi.org/10.1016/j.ebiom.2020.102969

10. Alban S. Adverse effects of heparin. Handb Exp Pharmacol 2012;207;211-263. https://doi. org/10.1007/978-3-642-23056-1_10

1. Yee J, Kaide CG. Emergency reversal of anticoagulation. West J Emerg Med 2019;20(5):770-783. https://doi.org/10.5811/westjem.2018.5.38235

12. Hoffman M. Heparins: Clinical use and laboratory monitoring. Labmedicine 2010;41(10):621-626. https://doi.org/10.1309/lmsxwc3a4lbijp2b

13. Merli GJ, Groce JB. Pharmacological and clinical differences between low-molecular-weight heparins: Implications for prescribing practice and therapeutic interchange. P T 2010;35(2):95-105. https://www. ncbi.nlm.nih.gov/pme/articles/PMC2827912/

14. Van der Meijden PEJ, Heemskerk JWM. Platelet biology and functions: New concepts and clinical 4. Van der Meijden PEJ, Heemskerk JWM. Platelet biology and functions: New concepts and
perspectives. Nat Rev Cardiol 2018;16(3):166-179. https://doi.org/10.1038/s41569-018-0110-0

15. Haile LA, Rao R, Polumuri SK, et al. PF4-HIT antibody (KKO) complexes activate broad innate immune and inflammatory responses. Thromb Res 2017;159:39-47. https://doi.org/10.1016/j.
immerile LA, Rao R, Polumuri SK, et al. PF-HIT antibody (KKO) complexes activate broad innate thromres.2017.09.018

thromres.2017.09.018
16. Warkentin TE. Laboratory diagnosis of heparin-induced thrombocytopenia. Int J Lab Hematol 2019;41(Suppl 1):15-25. https://doi.org/10.1111/ijlh.12993

17. Warkentin TE, Levine MN, Hirsh J, et al. Heparin-induced thrombocytopenia in patients treated with low-molecular-weight heparin or unfractionated heparin. N Engl J Med 1995;332:1330-1336. https:// doi.org/10.1056/nejm199505183322003

18. Watson H, Davidson S, Keeling D. Guidelines on the diagnosis and management of heparin-induced thrombocytopenia: second edition. Br J Haematol 2012;159(5):528-540. https://doi.org/10.1111/ bjh. 12059

19. Lo GK, Juhl D, Warkentin TE, Sigouin CS, Eichler P, Greinacher A. Evaluation of pre-test clinical score ( 4 T's) for the diagnosis of heparin-induced thrombocytopenia in two clinical settings. J Thromb Haemost 2006;4(4):759-765. https://doi.org/10.1111/j.1538-7836.2006.01787.x

20. Morris TA, Castrejon S, Devendra G, Gamst AC. No difference in risk for thrombocytopenia during treatment of pulmonary embolism and deep venous thrombosis with either low-molecularweight heparin or unfractionated heparin. Chest 2007;132(4):1131-1139. https://doi.org/10.1378/ chest.06-2518

21. Cuker A, Arepally GM, Chong BH, et al. American Society of Hematology 2018 guidelines for Cuker A, Arepally GM, Chong BH, et al. American Society of Hematology 2018 guidelines for
management of venous thromboembolism: Heparin-induced thrombocytopenia. Blood Adv 2018;2(22):3360-3392. https://doi.org/10.1182/bloodadvances.2018024489

22. Cuker A, Gimotty PA, Crowther MA, Warkentin TE. Predictive value of the 4Ts scoring system for . Cuker A, Gimotty PA, Crowther MA, Warkentin TE. Predictive value of the 4Ts scoring system for
heparin-induced thrombocytopenia: A systematic review and meta-analysis. Blood 2012;120(20):4160heparin-induced thrombocytopenia: A systematic review

23. Minet V, Dogne JM, Mullier F. Functional assays in the diagnosis of heparin-induced thrombocytopenia: A review. Molecules 2017;22(4)617. https://doi.org/10.3390/molecules22040617

24. Daviet F, Guervilly C, Baldesi O, et al. Heparin-induced thrombocytopenia in severe COVID-19. Circulation 2020;142(19):1875-1877. https://doi.org/10.1161/circulationaha.120.049015

25. World Health Organization. WHO Coronavirus (COVID-19) dashboard. https://covid19.who.int/ (accessed 21 June 2021).

26. Mustafa F, Giles R, Pepper MS. Rapid evolution of our understanding of the pathogenesis of COVID-19: Implications for therapy. S Afr Med J 2020;110(12):1180-1185. https://doi.org/10.7196/ SAMJ.2020.v110i12.15328

27. Avila J, Long B, Holladay D, Gottlieb M. Thrombotic complications of COVID-19. Am J Emerg Med 2021;39:213-218. https://doi.org/10.1016/j.jem.2020.09.065

28. Spyropoulos AC, Levy JH, Ageno W, et al. Scientific and Standardization Committee communication: Clinical guidance on the diagnosis, prevention, and treatment of venous thromboembolism in hospitalized patients with COVID-19. J Thromb Haemost 2020;18(8):1859-1865. https://doi. org/10.1111/jth.14929

29. Mendelson M, Boloko L, Boutall A, et al. Clinical management of COVID-19: Experiences of the COVID-19 epidemic from Groote Schuur Hospital, Cape Town, South Africa. S Afr Med J 2020;110(10):973-981. https://doi.org/10.7196/SAMJ.2020.v110i10.15157

30. Greinacher A, Thiele T, Warkentin TE, Weisser K, Kyrle PA, Eichinger S. Thrombotic thrombocytopenia a Greinacher A, Thiele T, Warkentin TE, Weisser K, Kyrle PA, Eichinger S. Thrombotic thrombocytopenia
after ChAdOx1 nCov-19 vaccination. N Engl J Med 2021;384:2092-2101. https://doi.org/10.1056/ nejmoa2 104840

31. Schultz NH, Sørvoll IH, Michelsen AE, et al. Thrombosis and thrombocytopenia after ChAdOx1 nCoV-19 vaccination. N Engl J Med 2021;384:2124-2130. https://doi.org/10.1056/nejmoa2104882

32. Scully M, Singh D, Lown R, et al. Pathologic antibodies to platelet factor 4 after ChAdOx1 nCoV-19 vaccination. N Engl J Med 2021;384:2202-2211. https://doi.org/10.1056/nejmoa2105385

33. Muir K-L, Kallam A, Koepsell SA, Gundabolu K. Thrombotic thrombocytopenia after Ad26.COV2.S vaccination. N Engl J Med 2021;384:1964-1965. https://doi.org/10.1056/nejmc2105869

34. Takuva S, Takalani A, Garrett N, et al. Thromboembolic events in the South African Ad26.COV2.S vaccine study. N Engl J Med 2021 (epub 2 June 2021). https://www.nejm.org/doi/full/10.1056/ NEJMc2107920

35. Cines DB, Bussel JB. SARS-CoV-2 vaccine-induced immune thrombotic thrombocytopenia. N Engl I Med 2021;384:2254-2256. https://doi.org/10.1056/nejme2106315

36. Jacobson BF, Schapkaitz M, Mar M, et al. Recommendations for the diagnosis and management of vaccine-induced immune thrombotic thrombocytopenia. S Afr Med J 2021;111(6):535-537. https:// doi.org/10.7196/SAMJ.2021.v111i6.15772

37. Nilius H, Kaufmann J, Cuker A, Nagler M. Comparative effectiveness and safety of anticoagulants for Nilius H, Kaufmann J, Cuker A, Nagler M. Comparative effectiveness and safety of anticoagulants for
the treatment of heparin-induced thrombocytopenia. Am J Hematol 2021;96(7):805-815. https://doi. org/10.1002/ajh.26194

38. Bates SM, Greer IA, Middeldorp S, Veenstra DL, Prabulos AM, Vandvik PO. VTE, thrombophilia, antithrombotic therapy, and pregnancy: Antithrombotic Therapy and Prevention of Thrombosis, 9th ed: American College of Chest Physicians Evidence-Based Clinical Practice Guidelines. Chest 2012;141(2 Suppl):e691S-e736S. https://doi.org/10.1378/chest.11-2300

39. Warkentin TE, Pai M, Linkins LA. Direct oral anticoagulants for treatment of HIT: Update of Hamilton experience and literature review. Blood 2017;130(9):1104-1113. https://doi.org/10.1182/ blood-2017-04-778993 